\title{
elsevier_RSAP_690
}

Original Research

\section{Examination of England's New Medicine Service (NMS) of complex health care interventions in community pharmacy}

Asam Latif $\mathrm{PhD}, \mathrm{MA}^{\mathrm{a}}$ *

Asam.Latif@nottingham.ac.uk

Justin Waring $\mathrm{PhD}, \mathrm{MSc}^{\mathrm{b}}$

Deborah Watmough ${ }^{c}$

Nick Barber PhD, MRPharmS, FRSM ${ }^{d}$

Anthony Chuter

James Davies PhD, M.Pharm

Nde-Eshimuni SalemaPhD, M.Pharm ${ }^{9}$

Matthew J. Boyd PhD, B.Pharm ${ }^{\circ}$

Rachel A. Elliott PhD, B.Pharm, FRPharmS

aSchool of Health Sciences, Queen's Medical Centre, Nottingham NG7 2UH, UK

${ }^{b}$ Centre for Health Innovation, Leadership \& Learning, Nottingham University Business School, Jubilee Campus, University of Nottingham, NG8 2BB, UK

'Division for Social Research in Medicines and Health, The School of Pharmacy, University of Nottingham, University Park, Nottingham NG7 2RD, UK

dThe Health Foundation, 90 Long Acre, London WC2E 9RA, UK

e68 Brighton Cottages, Copyhold Lane, Lindfield, Haywards Heath RH16 1XT, UK

fUCL School of Pharmacy, Department of Practice and Policy, Brunswick Square, London WC1N 1AX, UK

gDivision of Primary Care, School of Medicine, University of Nottingham, University Park, Nottingham NG7 2RD, UK

${ }^{*}$ Corresponding author.

Declaration of competing interests: The authors have no competing interests to declare.

\section{Abstract}

\section{Background}

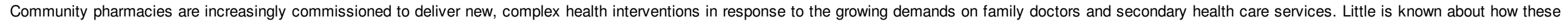

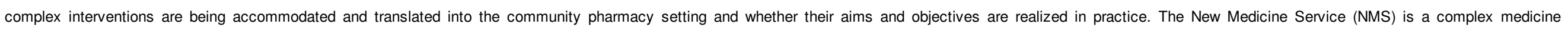
management intervention that aims to support patients' adherence to newly prescribed medicines for a long-term condition.

\section{Objective}

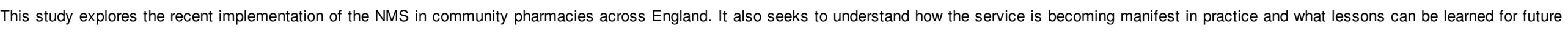
service implementation. 


\section{elsevier_RSAP_690}

Methods

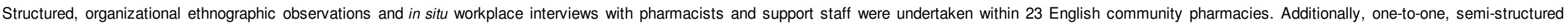

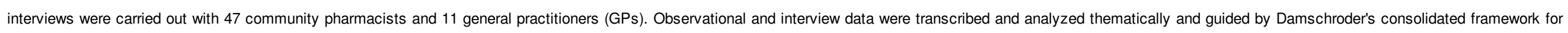
implementation research.

\section{Results}

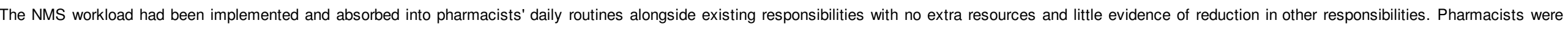

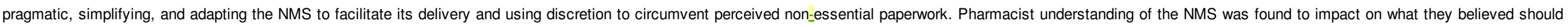

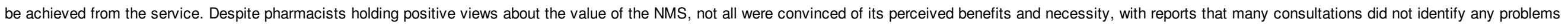
with the patients' medicines. GPs were generally supportive of the initiative but were unaware of the service or potential benefits. Poorly developed existing pharmacist-GP relationships impeded implementation.

\section{Conclusions}

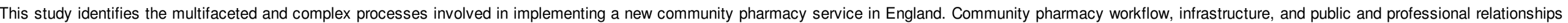

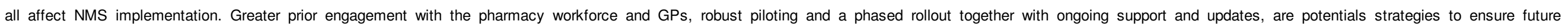
implementation of pharmacy services meet their intended aims in practice.

Keywords: New Medicine Service (NMS); Complex intervention; Implementation research; Community pharmacy

\section{Background}

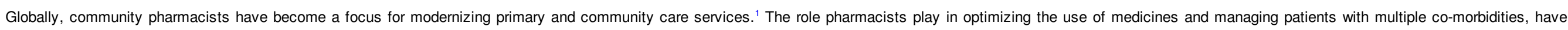

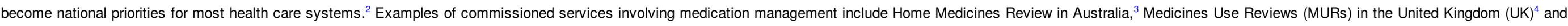

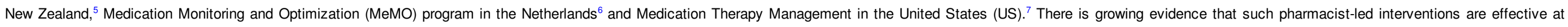
improving medicines usage and health outcomes. ${ }^{8-10}$

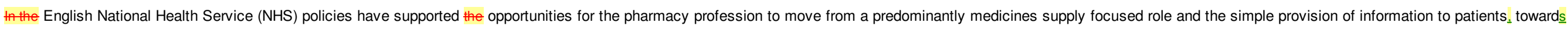

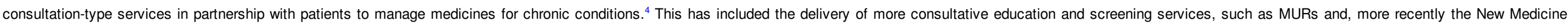

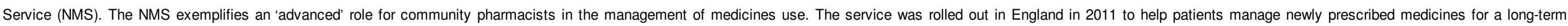

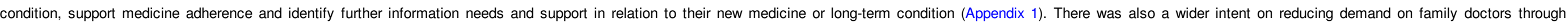

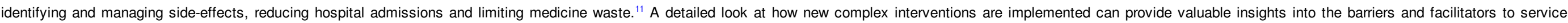

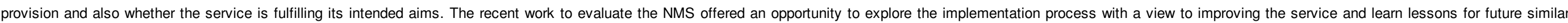

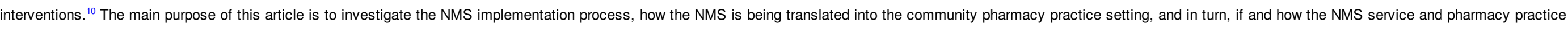
are transformed in practice.

\section{Complex interventions and the NMS}

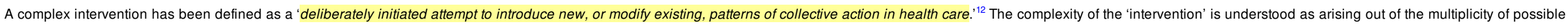

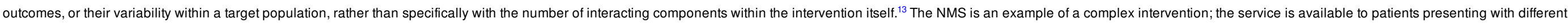

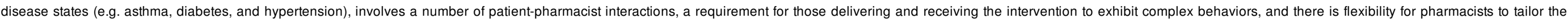
intervention to individual patients.

\section{Service description}

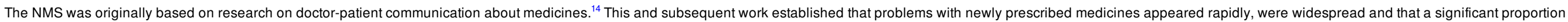




\section{elsevier_RSAP_690}

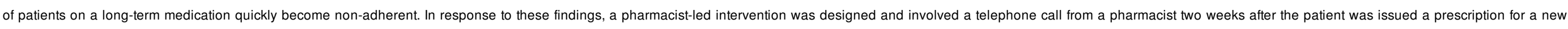
medicine. The service was shown to improve medicine adherence and was developed into the NMS. ${ }^{15}$

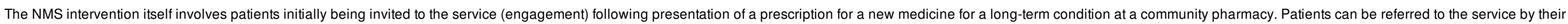

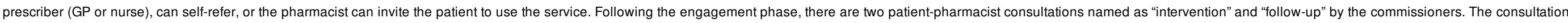

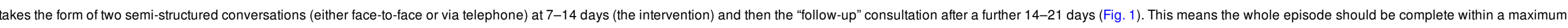

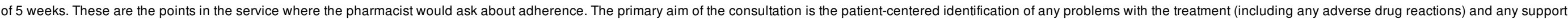

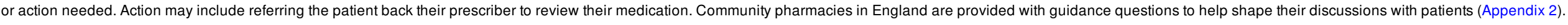

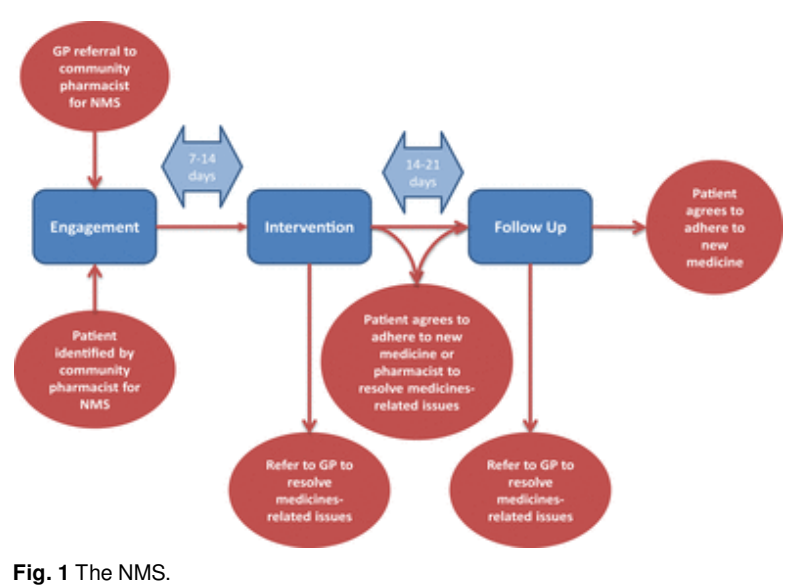

\section{Overview of the New Medicine Service (NMS) evaluation study}

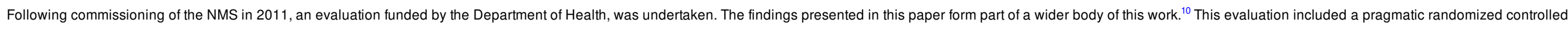

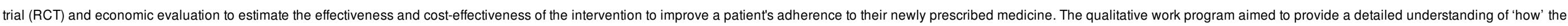

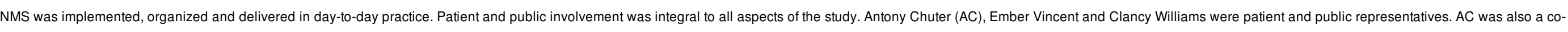
investigator. By attending meetings in person, these representatives were able to challenge and inform study design and findings, bringing their lay experience and expertise to the work.

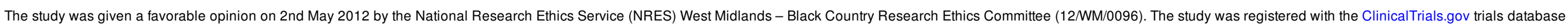
on 19th June 2012. Trial reference number NCT01635361 (http://clinicaltrials.gov/ct2/show/NCT01635361).

\section{Method}

\section{Theoretical framework}

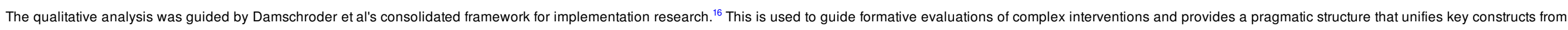

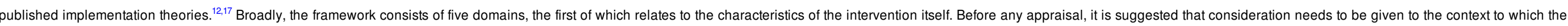

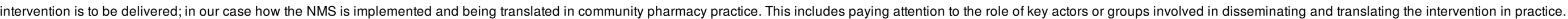

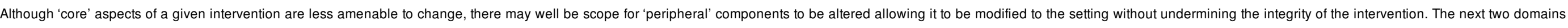

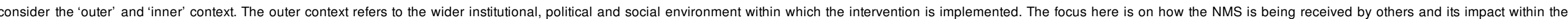

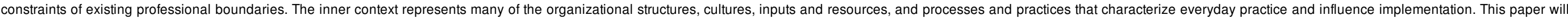

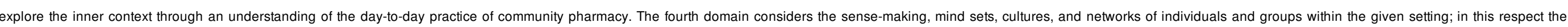




\section{elsevier_RSAP_690}

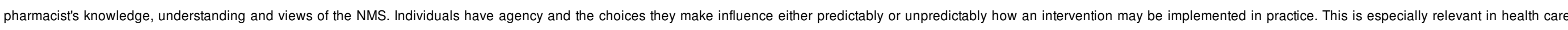

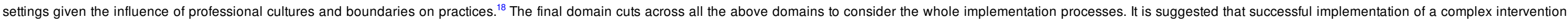
usually requires an active change process aimed at achieving individual and organizational level use of the intervention as designed.

\section{Sampling of community pharmacies}

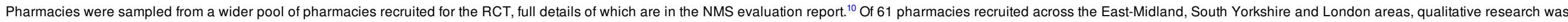

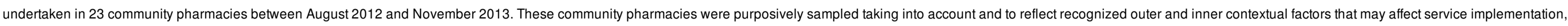
including pharmacy ownership type (independent, small and large multiples, supermarkets), geographical area and social deprivation (see Table 1).

\section{Table 1 Demographics of pharmacies profiled $(n=23)$}

\begin{tabular}{|c|c|}
\hline Pharmacy characteristic & Number \\
\hline \multicolumn{2}{|l|}{ Pharmacy type } \\
\hline Independent & 7 \\
\hline Supermarket & 1 \\
\hline Small multiple & 7 \\
\hline Large multiple & 8 \\
\hline \multicolumn{2}{|l|}{ Location } \\
\hline Nottinghamshire & 6 \\
\hline Derbyshire & 1 \\
\hline South Yorkshire & 5 \\
\hline Leicestershire & 1 \\
\hline London & 10 \\
\hline \multicolumn{2}{|l|}{ Setting } \\
\hline Urban & 14 \\
\hline Suburban & 9 \\
\hline \multicolumn{2}{|l|}{ Co-location with surgery } \\
\hline Co-located & 8 \\
\hline Not co-located & 15 \\
\hline Mean (range) Economic Deprivation Index for sample of pharmacies profiled ${ }^{a}$ & $25.18(4.41-60.03)$ \\
\hline
\end{tabular}

${ }^{a}$ Economic Deprivation Index (Score) - Score is proportional to level of deprivation. A higher score indicates an area of higher deprivation (English deprivation scores range from 0.5 to 87.8 ).

\section{Observations}

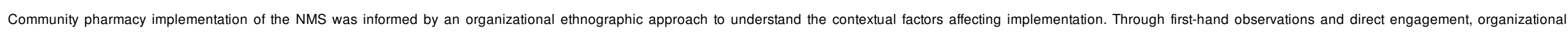

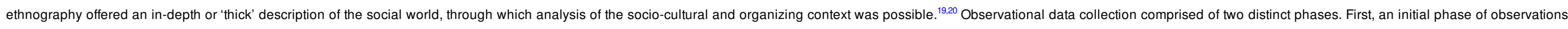

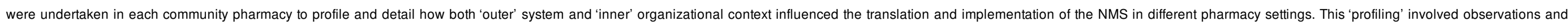




\section{elsevier_RSAP_690}

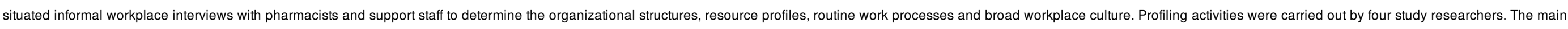

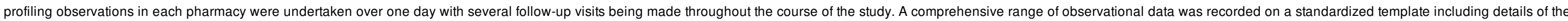

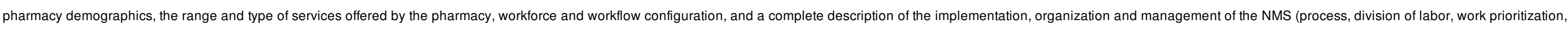

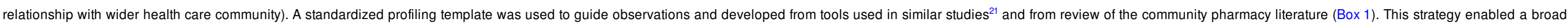
basis for comparison between study sites from which further in-depth analysis of the organization and delivery of the NMS was analyzed.

Box 1 Ethnographic-oriented observations that were made during profiling of pharmacies

$$
\text { - Space: }
$$

- Description of pharmacy location (i.e. urbanssuburbanrurual)

- Depiction of shop environment (i.e. size, types of retail items sold, location of health care counter, dispensary, consultation room)

- Actors/pharmacy activities:

- Reported number of pharmaciststlispensing stafticounter assistants typically on duty

- Average number of prescription items dispensed per month

- Range of pharmacy services offered

- Details of pharmacist and staff activities both reported and observed (i.e. profoessional prescripition checks, management duties, assembly of nursing homes medicines etc.

\section{- NMS observations:}

- Descripition of system/procoedure in place to implement NMS

- Methods of patient recruitment and details of patient engagement

- Estimated \% of face- to-facetelephone interventions

Organization \& management relating to the NMS:

- Workforce configuration \& division of labor

- Work prioritization

- Strategic organizational priorities for NMS

- Management roles and processes

- Relationship with wider health care community

- Exploration of diffusion of innovations:

- Agenda-setting (i.e. Decision making and adoption of NMS)

- Matching (i.e. What problem or need in the organization was matched with the innovation?

- Redesigningrrestructuring (i.e. What difusionddissemination stratagegies were used? 


\section{elsevier_RSAP_690}

- Claritying (i.e. implementation as per protocol/policy?)

- Routinizing (i.e. Extent NMS is a routine part of workload)

Exploration of the barriers and facilitators to the service

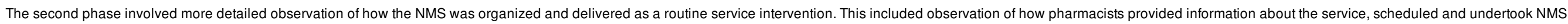

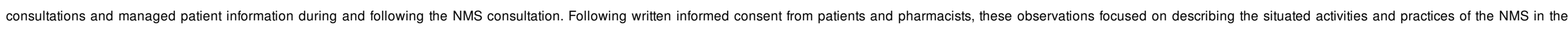
different pharmacies in order to identify and understand how the implementation processes led to variations in service delivery. Both phases of observations provided the foundations for subsequent formal pharmacist and GP interviews.

\section{Pharmacist and GP interviews}

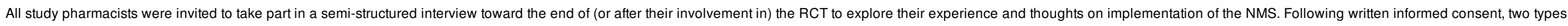

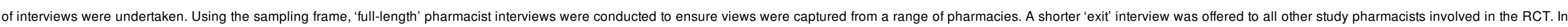

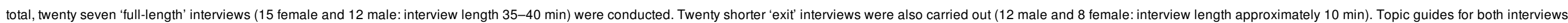
were tailored to clarify, confirm and extend the observational profile data (Boxes 2 and 3 ).

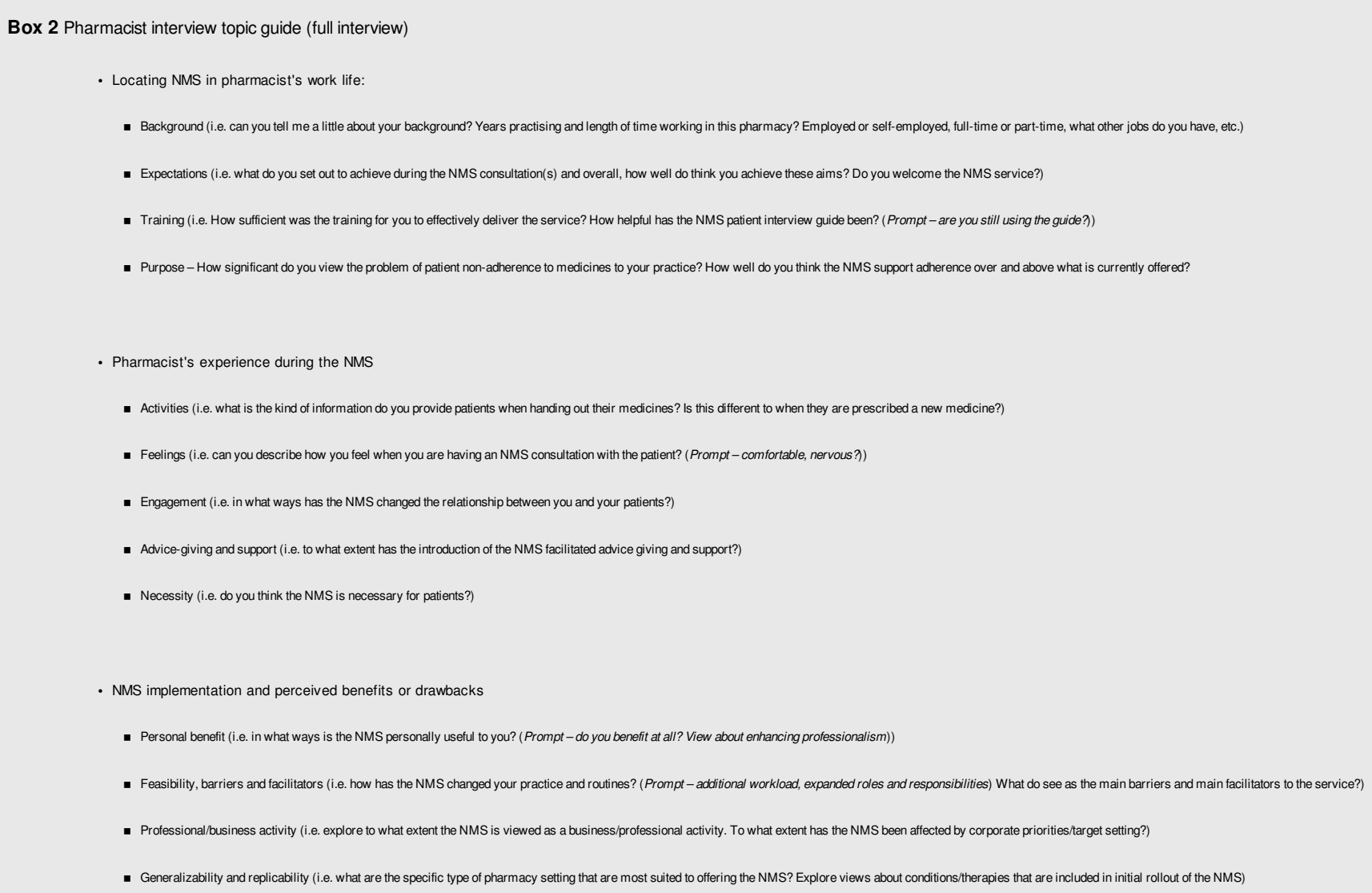




\section{elsevier_RSAP_690}

- Pharmacovigilance (i.e. explore awareness of patients reported side-effects/sadverse effects. Can you tell me about any examples where you have acted on an adverse event tas a result of an NMS? (Prompt - Have you ever filledina Yellow-reports as ar result?)
- Relationships with other stakeholders
Any final comments? Thank the pharmacist for their time.

Box 3 Pharmacist interview topic guide (exit interview)

$$
\text { - Pharmacist's experience during the NMS }
$$

- Expectation and purpose (i.e. From your perspective what is the purpose of the NMS?)

- Have you make any local changes to the way you deliver the NMS?

- Supporting adherence (i.e. how well do you think the NMS support adherence over and above what is currently offered through counseling or an MUR?)

- Interview schedule (i.e. to what extent do you use the NMS interview scheodule?

- What do see as the main barrier and main facilitator to the service? What would you change about the service?

\section{- Patient sample recruited to the study}

- Experience of recruting patients to the study (i.e. what was easy and what was hard? To what extent did the tranining day prepare you to recruit paients? D Did you appreciate being taken out of the pharmacy or could this be done in the pharmacy?)

- Sample of patients recruited (i.e. In your opinion, are there any differences in patient characcerisitics who acceptedddeclined to take part in the study i.e. those who 1. declined the service \& decline to take part in study, 2. accept NMS but decline to toke part in study, 3. acceppt service \& acceppt taking part in study)

- Up skiling: explore whether the pharmacist feels that they have been 'up skilled' in any way as aresult of taking part in the training -i.e. are they pertorming NMS the same now as they were before they started the study.

Any final comments? Thank the pharmacist for their time.

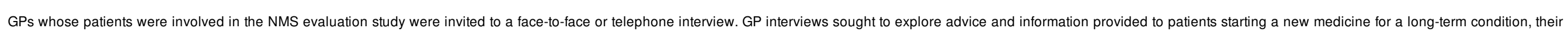

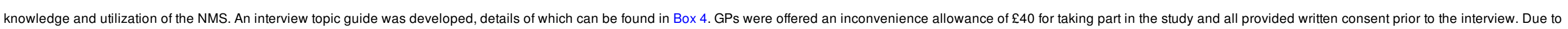

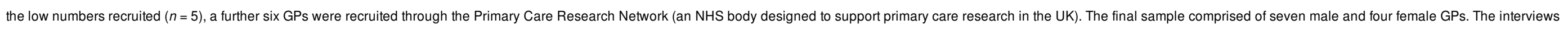
lasted 35-40 min, with nine conducted over the telephone, two face-to-face, one at the GP practice and one at a local research office.

\section{Box 4 GP interview guide}

- Locating the GP's work life

- Background (i.e. can you tell me a little about your background? How long have you practised as a GP and have worked in this practice?)

- GP's opinions about patient adherence to new medicines

- About new medicines (i.e. what kind of initormation do you provide to patients who are prescribed a new medicine? (Prompt - is this verbal/written?)) 


\section{elsevier_RSAP_690}

- About adherence (i.e. in your practice, how prevalent is patient non-adherence to new medicines? Why do you think this occurs? In your experience what types of patients are seen to adhere less with their medicines?

- GP views on the pharmacist's role

- Inter-professional relationships (i.e. do you have many interactions with the pharmacists in your dalily work? What are the interactions about? How would you describe your existing relationship with the pharmacy? Has the service in any way affected existing relationships with the pharmacist?)

- About pharmacist's role (i.e. what do believe the role of the pharmacist should be once a new medicine has been prescribed by you??)

- GP's opinions about the NMS

- Awareness (i.e. Prior to taking part in the study, had you heard about the NMS? If so, where from?

- Perceived purpose (i.e. what do believe is the purpose of the NMS is? How do you think the NMS could be improved for your patients and for you? Under what circumstances would you recommend that the patient take part in the NMS? Do you welcome the NMS service?

- Feedback from others

- Feedback (i.e. have you had any feedback from patientis refererrals from pharmacists? If so what was the outcome?)

Feasibility

- NMS and the surgery (i.e. to what extentin what ways has the NMS affected your practice? What do you like most tabout the servicelwhat do you like the least? Should pharmacists be involved with the service? (Prompt: is this a repeetitions of what is arready being done? A Are nurses better placed to do it??)

- Replicability (i.e. to what extent do you agree with the DH strategy to identily these patients for NMS (asthma/COPD; HTN, diabetes and anti-coagalatalelets? Do you think NMS should be extended to other disease indications?))

Any final comments? Thank GP for their time.

\section{Data analysis}

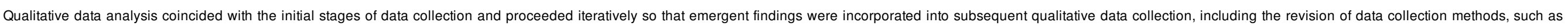

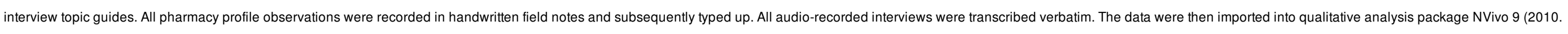

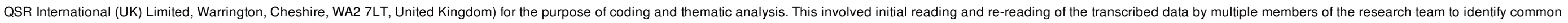

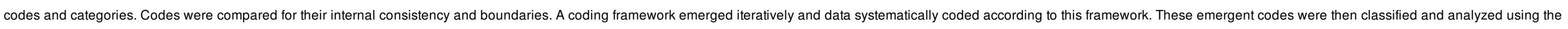

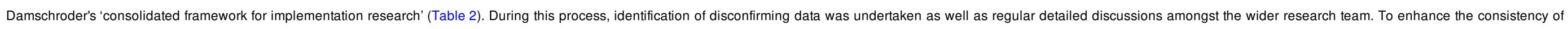

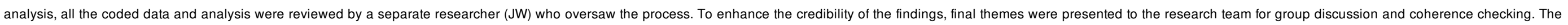
principle of constant comparison was used to test and refine the empirical conceptual consistency of codes and themes which were synthesized and narrated..$^{22}$

Table 2 Classification of thematic codes based on Damschroder's (2009) Consolidated Framework for Implementation Research (CFIR)

CFIR construct Short description of CFIR construct
Description of code within dataset

$(\mathrm{O})=$ Derived from pharmacy observation dataset

$(P)=$ Derived from pharmacist interview dataset

$(G)=$ Derived from GP interview dataset 
A. Intervention source

B. Evidence strength \& quality

C. Relative advantage

\section{E. Trialability}

F. Complexity
Perception of key stakeholders about whether the intervention is externally or internally developed.

Stakeholders' perceptions of the quality and validity of evidence supporting the belief that the intervention will have desired outcomes.

Stakeholders' perception of the advantage of implementing the intervention versus an alternative solution.

The degree to which an intervention can be adapted, tailored, refined, or reinvented to meet local needs.

The ability to test the intervention on a small scale in the organization and to be able to reverse course (undo implementation) if warranted.

Perceived difficulty of implementation, reflected by duration, scope radicalness, disruptiveness, centrality, and intricacy and number of steps required to implement.
Patients declining the service or service not acceptable to patients $(O)$ Barrier to NMS - service perceived as not necessary $(O)$ Views of significance of non-adherence/need for service? (P)

Repetition of existing services (G)

Pharmacy staff reported clientele of pharmacy $(\mathrm{O})$

Pharmacist NMS training $(\mathrm{O})$

Barrier to NMS - problems with identification of eligible patients (O)

Barrier to NMS - NMS appointments \& scheduling telephone calls (O)

Barrier to NMS - Patients declining the service or service not acceptable to patients (O)

Barrier to NMS - service perceived as not necessary $(\mathrm{O})$

Barrier to NMS - clientele of the pharmacy not receptive $(P)$

Significance of non-adherence/questioning the need for service $(P)$

Inclusivity - views on NMS disease categories $(P)$

Exclusion of seldom heard voice communities $(P)$

View on patient medicine adherence - prevalence and reasons for non-

adherence (G)

Types of patients who are less adherent $(G)$

View on disease state included in the NMS (G)

Repetition of existing services $(G)$

Barrier to NMS - patients declining the service or service not acceptable to patients $(\mathrm{O})$

Barrier to NMS - service perceived as not necessary (O)

Barrier to NMS - logistics of delivering service $(P)$

Views of significance of non-adherence/need for service? $(P)$

Duplication of GP work (P)

Success stories as result of NMS $(P)$

NMS makes it easier to give advice $(P)$

Increased awareness of patients reporting side effects or adverse effects $(P)$ GP time pressure $(G)$

What the pharmacy environment communicate to patients $(\mathrm{O})$

NMS high/Low fidelity (O)

NMS consultations and interview schedule $(\mathrm{O})$

NMS facilitators - adaptation of NMS to suit pharmacist circumstances $(O)$

NMS facilitators - service design $(O)$

NMS facilitators - delivery by phone calls $(\mathrm{O})$

Guidance questions and their use $(P)$

NMS can be done at quite working periods $(P)$

Services recently introduced/history of innovation (O)

Pharmacist NMS training $(\mathrm{O})$

NMS routinization $(\mathrm{O})$

Technology to identify patients $(\mathrm{O})$

Patient identification \& recruitment $(O)$

Barrier to NMS - problems contacting patients $(\mathrm{O})$

Barrier to NMS - PharmaBase usage $(\mathrm{O})$

Barrier to NMS - lack access to medical records $(\mathrm{O})$

Barrier to NMS - patient language barriers $(O)$

Barrier to NMS - logistics of delivering service $(P)$

NMS facilitators - simple to perform and record $(O)$ 
NMS facilitators - adaptation of NMS to suit pharmacist circumstances $(O)$

NMS facilitators - service design $(O)$

Need to incentivize GPs (P)

Type of pharmacy settings that are suitable for delivering the NMS $(P)$

Costs of the intervention and costs associated with implementing that intervention including investment, supply, and opportunity costs.
Barrier to NMS - resource limitations to provide service (O) Barrier to NMS - service perceived as not necessary $(O)$ Business/NMS targets $(P)$

\section{Outer setting}

A. Patient needs \& resources

B. Cosmopolitanism

C. Peer pressure

D. External policy \& incentives

\section{Inner setting}

A. Structural characteristics

B. Networks \& communications
The extent to which patient needs, as well as barriers and facilitators to meet those needs are accurately known and prioritized by the organization.

The degree to which an organization is networked with other externa organizations.

Mimetic or competitive pressure to implement an intervention; typically because most or other key peer or competing organizations have already implemented or in a bid for a competitive edge.

A broad construct that includes external strategies to spread interventions including policy and regulations (governmental or other central entity), extern mandates, recommendations and guidelines, pay-for-performance, collaboratives, and public or benchmark reporting.

The social architecture, age, maturity, and size of an organization.

Pharmacy image and cleanliness $(\mathrm{O})$

Organization of non-NMS workflow (O)

Operationalising the NMS $(\mathrm{O})$

NMS routinization $(\mathrm{O})$

Pharmacy infrastructure issues/problems $(\mathrm{O})$

The nature and quality of webs of social networks and the nature and quality of formal and informal communications within an organization.

Referrals to GP $(\mathrm{O})$
Pharmacy staff reported clientele of pharmacy (O)

Technology to identify patients $(\mathrm{O})$

ngaging patients with NMS $(\mathrm{O})$

Problems with identification of eligible patients $(\mathrm{O})$

PMS consultations and interview schedule (O)

Patients declining the service or service not acceptable to patients $(\mathrm{O})$

Barrier to NMS - problems contacting patients $(\mathrm{O})$

Barrier to NMS - lack of access to seldom heard community groups $(\mathrm{O})$ 政

reluctant $(\mathrm{P})$

(D) become

NMS encourages patient communication in busy pharmacy $(P)$

Health care advice and services available $(O)$

Technology to ID patients $(\mathrm{O})$

Barrier to NMS - consistency of pharmacies offering NMS $(O)$

Barrier to NMS - Lack of motivation and influence of targets $(P)$

NMS facilitators - two pharmacists on duty $(\mathrm{O})$

Business/NMS targets $(P)$

alizing for pharmacy $(P)$

Barrier to NMS - lack of public awareness $(\mathrm{O})$

Reaction of GPs/other health care professionals $(P)$

Need to incentivize GPs $(P)$

Awareness of NMS (G)

Effect of NMS on GP's practice $(G)$ 


\section{elsevier_RSAP_690}

C. Culture

\section{Implementation climate}

1. Tension for change

2. Compatibility

3. Relative priority

4. Organizational incentives \& rewards

5. Goals and feedback

6. Learning climate
Norms, values, and basic assumptions of a given organization.

The absorptive capacity for change, shared receptivity of involved individuals to an intervention and the extent to which use of that intervention will be rewarded, supported, and expected within their organization.

The degree to which stakeholders perceive the current situation as intolerable or needing change.

The degree of tangible fit between meaning and values attached to the intervention by involved individuals, how those align with individuals' own norms, values, and perceived risks and needs, and how the intervention fits with existing workflows and systems.

Individuals' shared perception of the importance of the implementation within the organization.

Extrinsic incentives such as goal-sharing awards, performance reviews, promotions, and raises in salary and less tangible incentives such as promotions, and raises in sal.
increased stature or respect.

A climate in which: a) leaders express their own fallibility and need for team members' which: a) leading valued, and knowledgeab partners in the change proces; $c$ ) individs psychologically safe to try new methods; and d) there is sufficient time and space for reflective thinking and evaluation.

The degree to which goals are clearly communicated, acted upon, and fed back to staff and alignment of that feedback with goals.
Pharmacy staff reported clientele of pharmacy $(\mathrm{O})$

What the pharmacy environment communicate to patients $(O)$

Barrier to NMS - staffing and pharmacist lack of time to deliver NMS (P)

NMS facilitators - personal motivation of pharmacist $(\mathrm{O})$

NMS facilitators - willing, competent staff and good implementation plan (O)

GP view of pharmacist wider involvement in medicines management $(G)$

Inter-professional collaboration (G)

What the pharmacy environment communicate to patients (O)

Operationalising the NMS $(\mathrm{O})$

GP lacks awareness/non supportive $(\mathrm{O})$

Barrier to NMS - lack inter-professional collaboration (O)

Barrier to NMS - staffing, workload and convenience limitations (O)

Barrier to NMS - patient awareness $(P)$

Barrier to NMS - staffing and pharmacist lack of time to deliver NMS (P)

NMS facilitators - personal motivation of pharmacist $(O)$

NMS facilitators - pharmacist perceives NMS outcomes positively $(\mathrm{O})$

NMS facilitators - two pharmacists on duty $(\mathrm{O})$

Public view of pharmacist as medicine suppliers $(P)$

NMS activities delegated to pre-registration pharmacist $(P)$

Need to incentivize GPs $(P)$

Inter-professional rivalry i.e. flu vaccination $(P)$

(

(PPacist undervalued) $(P)$

PP not aw of what phamacist does or what $(P)$

Reblems with professional boundaries (P)

Remoteness of the pharmacy from GP practice $(P)$

Effect of NMS on GP's practice (G)

GP view of pharmacist wider involvement in medicines management $(G)$

Inter-professional collaboration (G)

Existing contact with pharmacist $(\mathrm{G})$

Engaging patients with NMS $(\mathrm{O})$

Barrier to NMS - increase workload and time $(P)$

NMS facilitators - pharmacist perceives NMS outcomes positively (O)

GP time pressure (G)

Pharmacy staff reported clientele of pharmacy $(\mathrm{O})$

Operationalising the NMS $(\mathrm{O})$

Barrier to NMS - poor implementation (O)

GP time pressure $(\mathrm{G})$

Retail focus of the pharmacy $(\mathrm{O})$

Business priorities and NMS (O)

NMS improves job satisfaction $(\mathrm{P})$

Retail focus of the pharmacy $(\mathrm{O})$

Barrier to NMS - patient awareness $(P)$

Patient relationships $(P)$

MMS consultations and interview schedule (O)

Up-skilling as a result of NMS (P) 


\section{elsevier_RSAP_690}

E. Readiness for implementation

Tangible and immediate indicators of organizational commitment to its decis to implement an intervention.

Commitment, involvement, and accountability of leaders and managers with the implementation.

The level of resources dedicated for implementation and ongoing operations including money, training, education, physical space, and time.

Ease of access to digestible information and knowledge about the intervention and how to incorporate it into work tasks.

Individuals' attitudes toward and value placed on the intervention as well as familiarity with facts, truths, and principles related to the intervention.

Individual belief in their own capabilities to execute courses of action to achieve implementation goals.

Characterization of the phase an individual is in, as he or she progresses toward skilled, enthusiastic, and sustained use of the intervention.

A broad construct related to how individuals perceive the organization and their relationship and degree of commitment with that organization.

A broad construct to include other personal traits such as tolerance of ambiguity, intellectual ability, motivation, values, competence, capacity, and learning style.

The degree to which a scheme or method of behavior and tasks for implementing an intervention are developed in advance and the quality of those schemes or methods.

A. Planning

\section{B. Engaging}

Attracting and involving appropriate individuals in the implementation and use of the intervention through a combined strategy of social marketing, education, role modeling, training, and other similar activities.

1. Opinion leaders

2. Formally appointed internal implementation leaders

3. Champions
Individuals in an organization who have formal or informal influence on the attitudes and beliefs of their colleagues with respect to implementing the intervention.

Individuals from within the organization who have been formally appointed with responsibility for implementing an intervention as coordinator, project manager, team leader, or other similar role.

Individuals who dedicate themselves to supporting, marketing, and 'driving through' an [implementation], overcoming indifference or resistance that the
Pharmacy image and cleanliness $(\mathrm{O})$

Views on the match between NMS aims and problems of medicine taking $(\mathrm{O}) /$ Not matched $(\mathrm{O})$

Business priorities and NMS $(\mathrm{O})$

NMS facilitators - provision of infrastructure to deliver NMS $(\mathrm{O})$

Professionalizing for pharmacy $(\mathrm{P})$

NMS facilitators - provision of infrastructure to deliver NMS $(\mathrm{O})$

NMS facilitators - two pharmacists on duty (O)

Adequacy of NMS training to deliver NMS $(P)$

Up-skilling as a result of NMS $(P)$

Views on the match between NMS aims and problems of medicine taking $(\mathrm{O}) /$ Not matched $(\mathrm{O})$

NMS consultations and interview schedule $(\mathrm{O})$

Views on the match between NMS aims and problems of medicine taking (O)/Not matched (O)

NMS as a means to improved patient care $(\mathrm{O})$

Patients declining the service or service not acceptable to patients $(\mathrm{O})$

NMS facilitators - local pharmaceutical committee training $(O)$

Barrier to NMS - Lack of motivation and influence of targets $(P)$

NMS high/Low fidelity (O)

NMS facilitators - make NMS a habit (O)

Organization of non-NMS workflow $(\mathrm{O})$

NMS planning (O)

NMS communication to staff $(\mathrm{O})$

Pharmacist NMS training $(\mathrm{O})$

Pharmacist NMS training $(O)$

to accommodate NMS (O)

NMS facilitators - provision of infrastructure to deliver NMS $(O)$

NMS facilitators - make NMS a habit (O)

Lack of prior notice about NMS $(\mathrm{P})$

\section{Services recently introduced/history of innovation $(\mathrm{O})$}

Pharmacist NMS training $(\mathrm{O})$

Maintenance of workflow during the NMS $(\mathrm{O})$

Lack of prior notice about NMS $(\mathrm{P})$

NMS facilitators - local pharmaceutical committee training $(\mathrm{O})$

NMS planning $(\mathrm{O})$

Services recently introduced/history of innovation (O)

NMS communication to staff $(\mathrm{O})$ yen 
4. External change agents

C. Executing

D. Reflecting \& evaluating intervention may provoke in an organization.

Individuals who are affiliated with an outside entity who formally influence or facilitate intervention decisions in a desirable direction.

Carrying out or accomplishing the implementation according to plan.
Eviaence or restructuring to accommoaate INIVIS (U)

Services recently introduced/history of innovation $(\mathrm{O})$ Pharmacy as innovator $(\mathrm{O})$

NMS communication to staff $(O)$

NMS appointments \& scheduling telephone calls $(\mathrm{O})$ NMS consultations and interview schedule (O)

Quantitative and qualitative feedback about the progress and quality of implementation accompanied with regular personal and team debriefing about implementation accompa
progress and experience.
Views on the match between NMS aims and problems of medicine taking $(\mathrm{O}) /$ Not matched $(\mathrm{O})$

NMS as a means to improved patient care $(\mathrm{O})$ Professionalizing for pharmacy $(P)$

\section{Results}

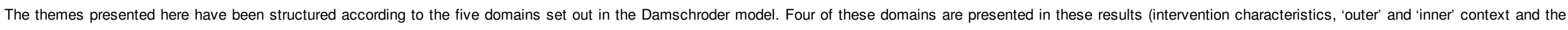

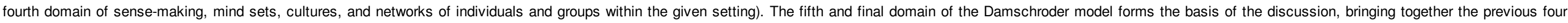
domains to consider the whole implementation processes.

\section{Domain 1: intervention characteristics and organizational setting}

Three themes emerged from the data that highlighted the importance of how the dynamics of the intervention itself impacted on patients and the way the NMS was delivered by those offering the service.

\section{These were:}

1. Public awareness of the NMS and problems with patient engagement with the service

2. Pharmacists' delivery of the NMS and use of the guidance questions

3. Circumventing 'paperwork' to deliver the service and a perceived overcomplicated payment claims processes

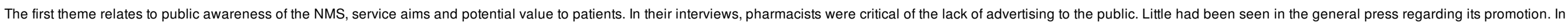
light of their existing identity of supplying medicines, engaging with patients about the NMS was challenging.

I think the main thing is just advertising the service ... we have leaflets and things like that but somehow the service still doesn't appeal ... there will be a percentage of people who will see pharmacists as just dispensers.

[Pharmacist 04-1, Full interview, Male, 55 years, Independent]

One main barrier would be you have to sometimes educate the patient on what it is you're actually going to be doing with them ... they sometimes think this a new trial drug? Is it actually safe? Has it been used before?

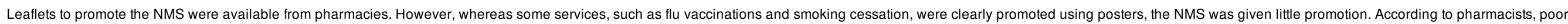

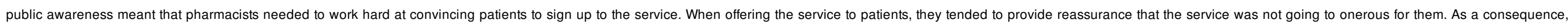

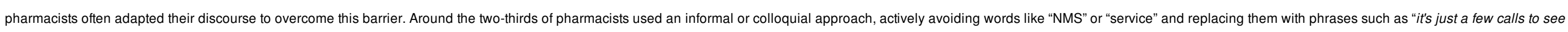
how you are doing."

Sometimes if you go through everything, it scares people away from it [NMS], and they say 'Oh I'm not signing up for it', when all you are doing is calling them up and asking for a quick chat, which is very informal, rather than trying to over formalise it.

[Pharmacist 63, Full interview, Male, 25 years, Small multiple]

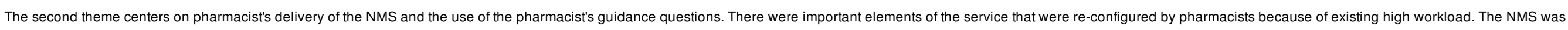

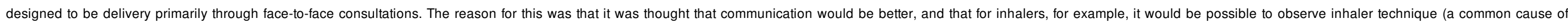

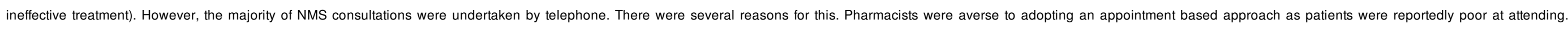




\section{elsevier_RSAP_690}

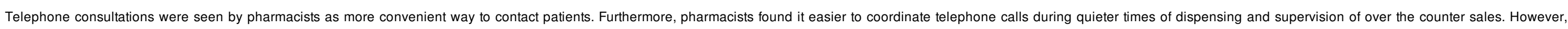
telephoning patients came with its own problems. Contacting patients was problematic and, if patients were called unexpectedly, participation in the discussion was perceived by pharmacists to be less useful.

I quite enjoy it; it doesn't take too much time. The most annoying thing is when you can't get hold of people and you call them like six times, they are just never in or answer the phone.

[Pharmacist 63, Full interview, Male, 25 years, Small multiple]

Also if it's an inconvenient time when you've called then you can tell by the answers. You know, "are there any problems?" "No". "Anything I can help you with?" "No". "It's very important you have a healthy lifestyle". "Yes I am". "Okay bye". And it's over in like a minute.

[Pharmacist 65, Exit interview, Male, 44 years, Small multiple]

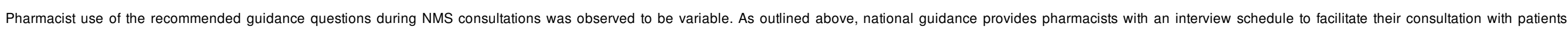

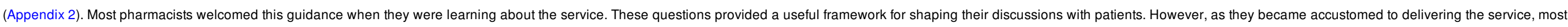

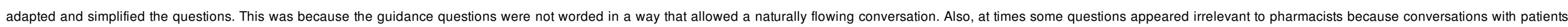
brought up unexpected issues that could not be simply managed by following a scripted interview guide.

I was trying really hard to ask the questions almost the way they were worded and it wasn't making for a natural flowing conversation. I do use that format but I've tweaked it a little bit to make it more me.

[Pharmacist 01, Full interview, Female, 38 years, Small multiple]

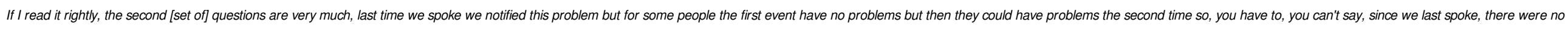
problems, you know

[Pharmacist 06, Exit interview, Male, 40 years, Large multiple]

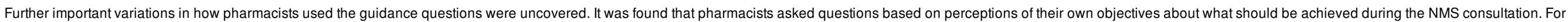
some the NMS was a way to support patients and to resolve medication problems which would have otherwise gone to the GP.

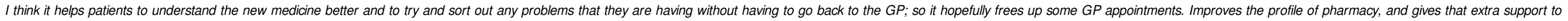
patients.

[Pharmacist 64, Full interview, Female, 37 years, Small multiple]

For others, the NMS was simply a monitoring or a 'checking' opportunity and to teach patients by providing further information.

It is just asking them if they know why that medicine has been prescribed; if they say 'no', start telling them some more information.

[Pharmacist 02, Full interview, Female, 27 years, Large multiple]

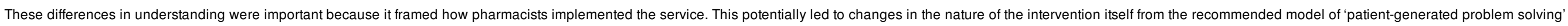
to simple advice giving.

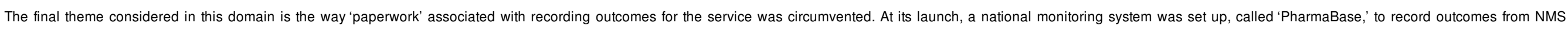

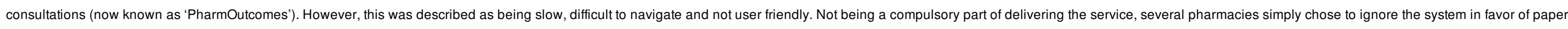
records and did not use this technology to enter the NMS consultation data.

It wasn't user-friendly [PharmaBase], it was not linked to the PMR [Patient Medication Record] you literally came out of your system and then go onto the PharmaBase. It's not already populated for you ...

[Pharmacist 03 (1), Full interview, Female, 49 years, Independent]

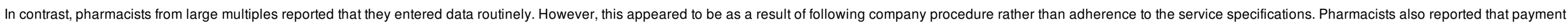

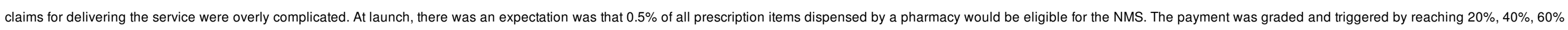
and $80 \%$ of targets within tiers of dispensing volume. 


\section{elsevier_RSAP_690}

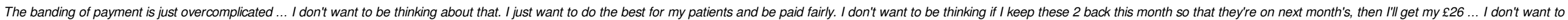
have to continually work the maths.

This payment structure was simplified a few months following the launch of the service to allow pharmacies to be remunerated for each completed NMS.

\section{Domain 2: implementing a new service within existing professional boundaries}

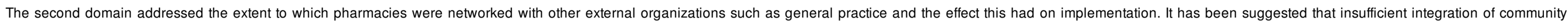

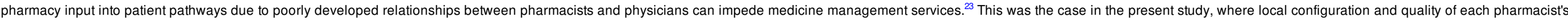

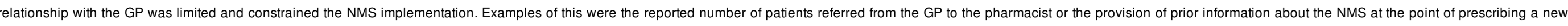

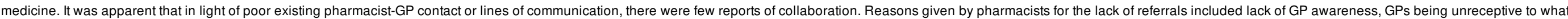

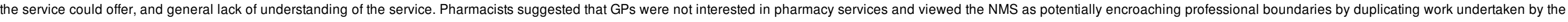
GP.

I went to a practice meeting last September/October 2012 to talk about New Medicine Service and Medicines Use Reviews. The nurse felt that we were actually duplicating and undermining the work that they were doing.

[Pharmacist 11, Full interview, Male, 33 years, Small multiple]

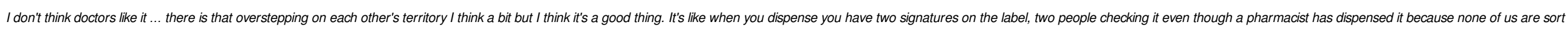
of infallible and I think it's good

[Pharmacist 04-2, Full interview, Female, 58 years, Independent]

This view was also reflected in the response of GPs, who were either unaware of the NMS, uncertain about its purpose, or confused the service with other more established pharmacy services such as MURs.

Have you heard about the NMS at all? [Researcher]

GP: Just remind me what it stands for? IIt stands for the New Medicine Service] I mean not really no, no if I'm going to be honest ..

[GP 06, Male, 26 years qualified]

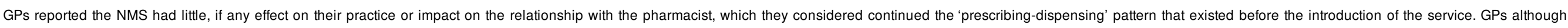

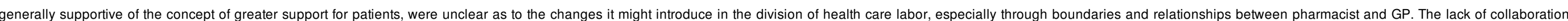

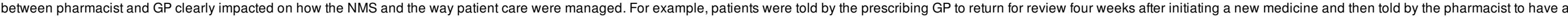

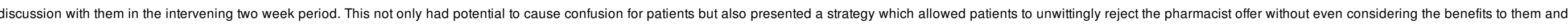
their health.

It's not uncommon for people to say I'm seeing the doctor, I'm seeing the nurse, again in a fortnight and they can't see the added value that the pharmacist would give.

[Pharmacist 70, Exit interview, Female, 48 years, Large multiple]

A barrier to the service to be honest is mainly when the doctor and nurse or someone is going to see the patient in the next 2 weeks, because then patients say 'well do I need to come here as well?'

[Pharmacist 75, Exit interview, Male, 37 years, Small multiple]

\section{Domain 3: inner pharmacy setting: accommodation of NMS and alignment with work practices}

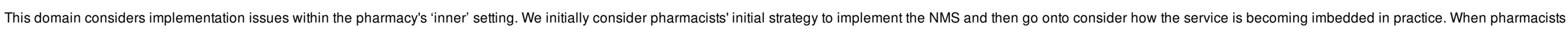

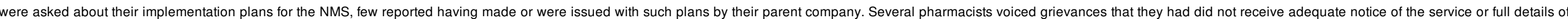
what the service involved: 


\section{elsevier_RSAP_690}

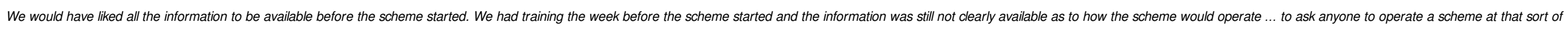
notice is atrocious planning really.

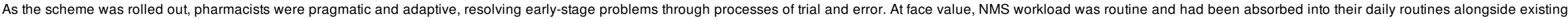

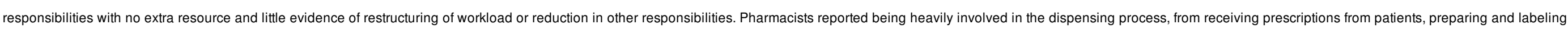

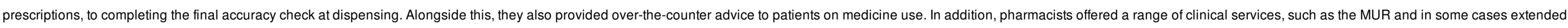

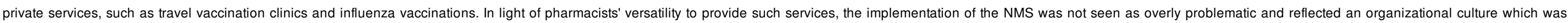
amenable and accepting of change. It was important to note, however, that accommodating the NMS was easier in pharmacies that had two pharmacists on duty as well as having perceived well-organized workflow systems.

Yes, I think time is the biggest one ... it is an additional thing that you have got to do.

I think if it was just one pharmacist here the day in and day out pressure would get you ... I think two pharmacists help here definitely. I think it would be too much on one pharmacist.

\section{Domain 4: pharmacists' views of the NMS}

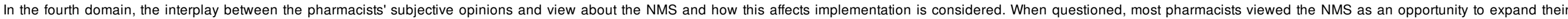

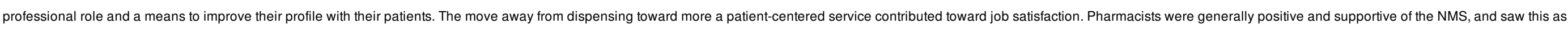
an opportunity to support and educate patients, as well as identify and mitigate potential health risks associated with medicine use:

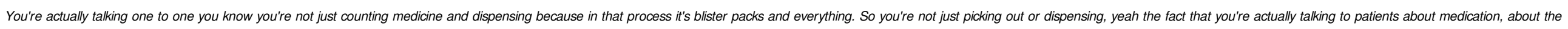
conditions, definitely is yes.

[Pharmacist 04-1, Full interview, Male, 55 years, Independent]

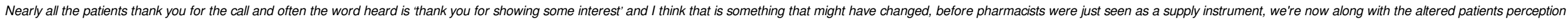
actually there to talk to as well and get asked questions and get information out of ...

[Pharmacist 06, Exit interview, Male, 40 years, Large multiple]

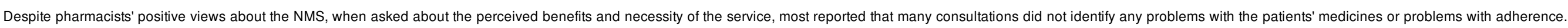

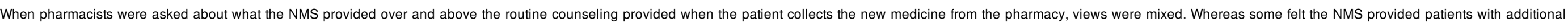
support and an opportunity to tackle issues early, others felt that as pharmacists, they should automatically be providing patients with such support and advice:

It makes no difference whether you do it formally or do it anyway because that's your job ... I think I suppose NMS forces you to do what you're supposed to be doing ... I would like to think that I'm working in no different way, whether NMS is there or not.

[Pharmacist 04-2, Full interview, Female, 58 years, Independent]

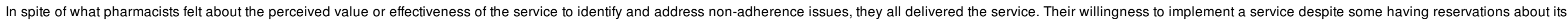

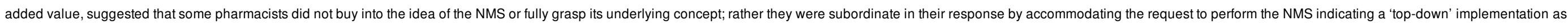
oppose to a 'bottom-up' commitment

\section{Discussion}

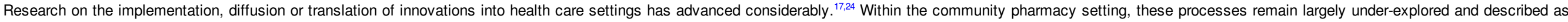

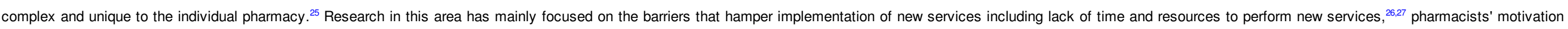




\section{elsevier_RSAP_690}

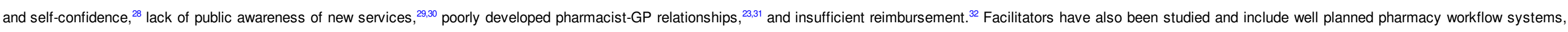

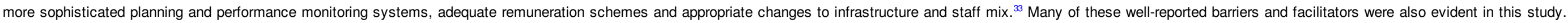

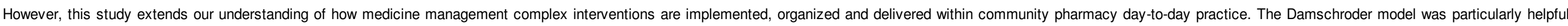

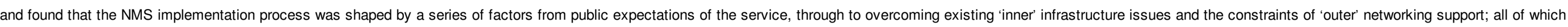

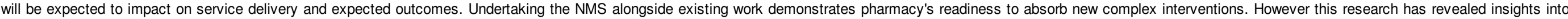
the strategies pharmacies use to overcome the practical challenges associated with delivery of a new service.

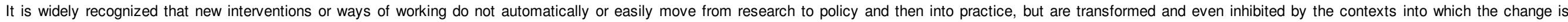

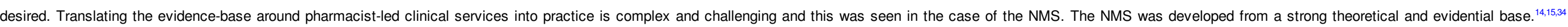

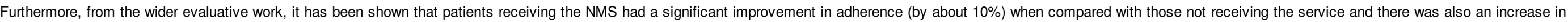

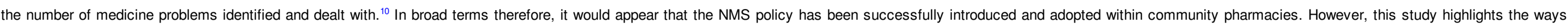

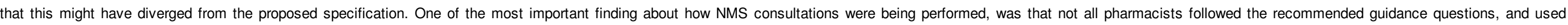

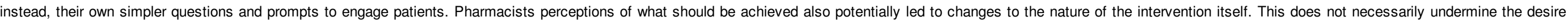

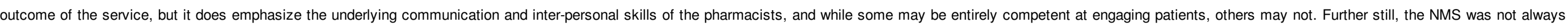

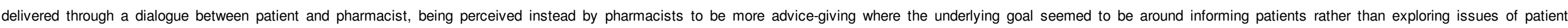

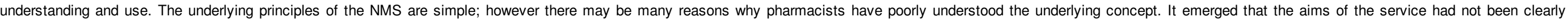

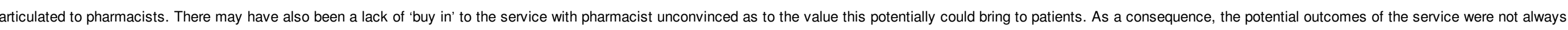

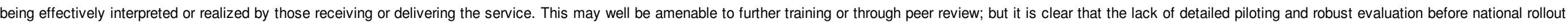
has made it more challenging to rectify these issues.

\section{Lessons for future service design and implementation}

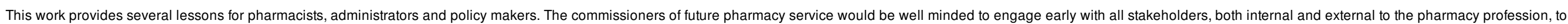

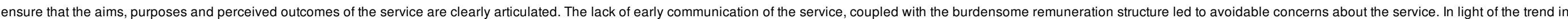

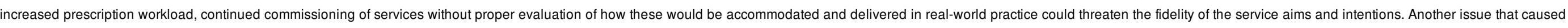

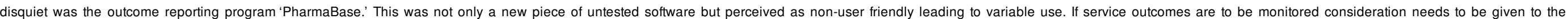

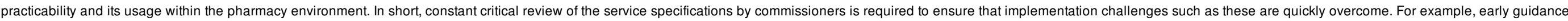

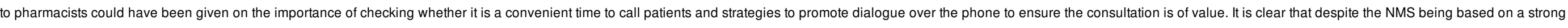

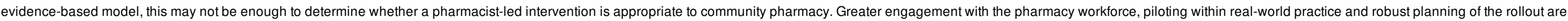
possible solutions to ensure future problems with new service implementation are overcome.

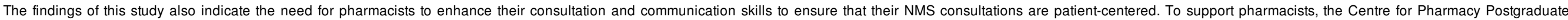

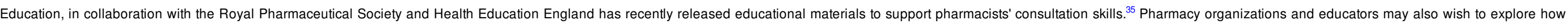

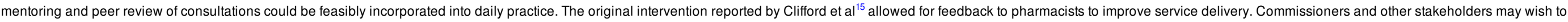
consider extra funding within the service structure to allow practitioners involved in offering the NMS to receive this feedback, mentoring and peer support.

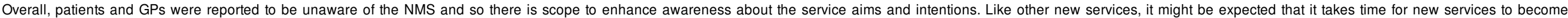

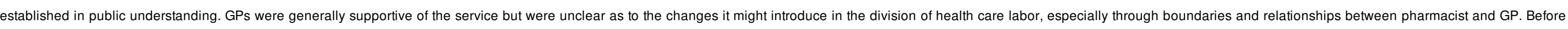

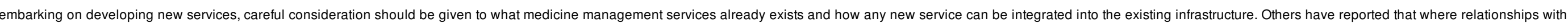

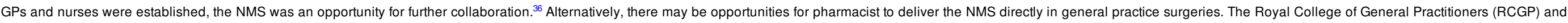
the Royal Pharmaceutical Society (RPS) have recently issued plan for pharmacists to work together as part of the general practice team to ease current pressures in general practice and address the severe shortage of GP's. ${ }^{37}$ 


\section{elsevier_RSAP_690}

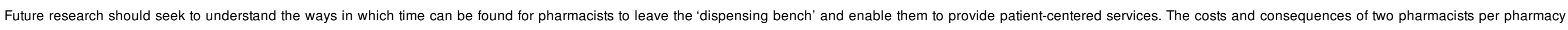

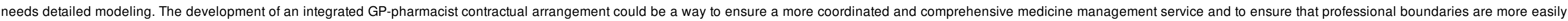
overcome.

\section{Strengths and limitations of the study}

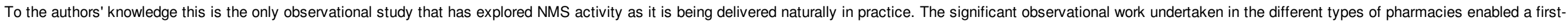

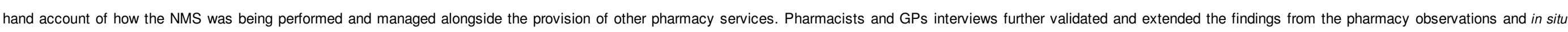

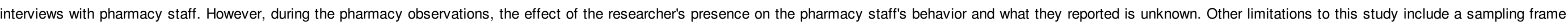

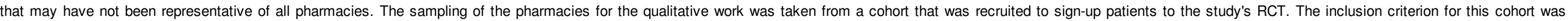

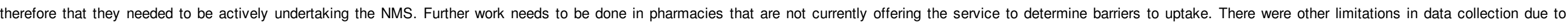
challenges of recruitment; in particular there were 11 GPs who responded to take part in an interview and so this may not be a representative view of GPs experience of the NMS.

\section{Conclusion}

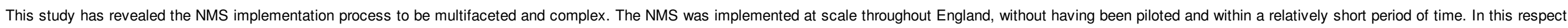

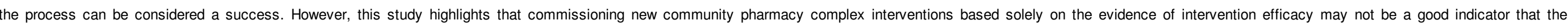

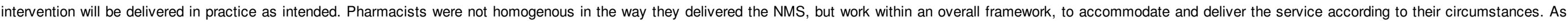

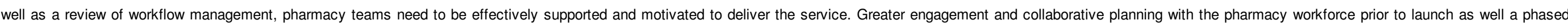

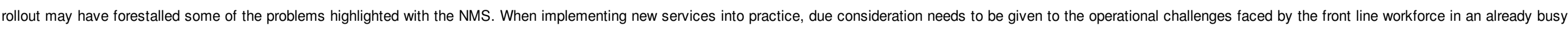

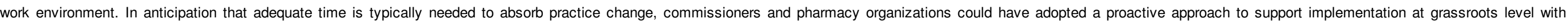
ongoing updates to pharmacy staff, GPs and patients to re-emphasize the need and aims of the service.

\section{Acknowledgments}

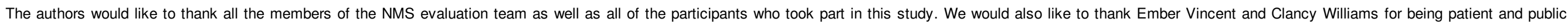
representatives in this study.

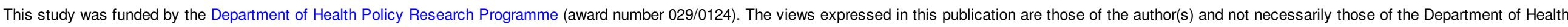

\section{Supplementary data}

Supplementary data related to this article can be found at http://dx.doi.org/10.1016/j.sapharm.2015.12.007.

\section{References}

1

P.P. George, J.A. Molina, J. Cheah, S.C. Chan and B.P. Lim, The evolving role of the community pharmacist in chronic disease management-a literature review, Ann Acad Med Singapore 39, 2010, 861-867.

. E. Sabaté, Adherence to Long-term Therapies: Evidence for Action, 2013, World Health Organization; Geneva.

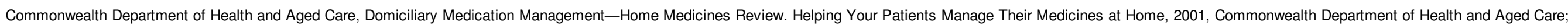
Canberra. 


\section{elsevier_RSAP_690}

. Department of Health, The Pharmaceutical Services (Advanced and Enhanced Services) (England) Directions, 2005, DH; London.

5

. E. Lee, R. Braund and J. Tordoff, Examining the first year of medicines use review services provided by pharmacists in New Zealand. 2008, NZ Med J 122, 2009, 1293.

6

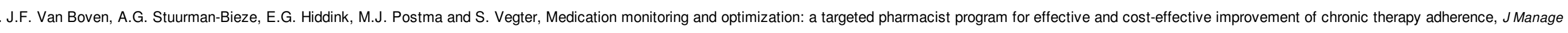
Care Pharm 20, 2014, 786-792.

7

. M.J. Barnett, J. Frank, H. Wehring, et al., Analysis of pharmacist-provided medication therapy management (MTM) services in community pharmacies over 7 years, J Manage Care Pharm 15, 2009 , 18.

8

. J.M.P. Horgan, A. Blenkinsopp and R.J. McManus, Evaluation of a cardiovascular disease opportunistic risk assessment pilot ('Heart MOT' service) in community pharmacies, J Public Health 32, 2010, 110-116.

9

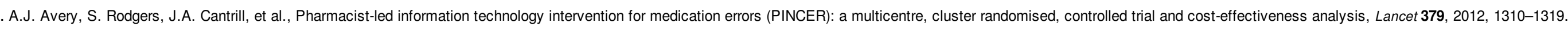
10

. R.A. Elliott, M.J. Boyd, J. Waring, et al., Department of Health Policy Research Programme Project 'Understanding and Appraising the New Medicines Service in the NHS in England (029/0124)',

2014 http://www.nottingham.ac.uk/ pazmjb/nms/downloads/report/files/assets/common/downloads/108842\%20A4\%20Main\%20Report.v4.pdf, Accessed 28.06.15.

11

. Pharmaceutical Services Negotiating Committee, New Medicines Service, 2011 http://www.psnc.org.uk/pages/nms.html, Accessed 28.06.15.

12

. C. May, T. Finch, F. Mair, et al., Understanding the implementation of complex interventions in health care: the normalization process model, BMC Health Serv Res 7, $2007,148$.

13

. P. Craig, P. Dieppe, S. Macintyre, S. Michie, I. Nazareth and M. Petticrew, Developing and evaluating complex interventions: the new Medical Research Council guidance, Int J Nurs Stud 50, 2013 , 587-592.

. N. Barber, J. Parsons, S. Clifford, R. Darracott and R. Horne, Patients' problems with new medication for chronic conditions, Qual Saf Health Care 13, 2004, 172-175.

15

. S. Clifford, N. Barber, R.A. Elliott, E. Hartley and R. Horne, Patient-centred advice is effective in improving adherence to medicines, Pharm World Sci 28, 2006, 165-170.

16

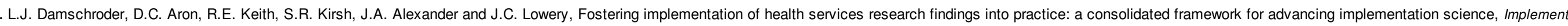
Sci 4, 2009, 50.

17

. T. Greenhalgh, G. Robert, F. Macfarlane, P. Bate and O. Kyriakidou, Diffusion of innovations in service organizations: systematic review and recommendations, Milbank Q 82, 2004, 581-629.

18

. E. Ferlie, The nonspread of innovations: the mediating role of professionals, Acad Manage $J$ 48, 2005, 117-134. 


\section{elsevier_RSAP_690}

19

N.K. Denzin and Y.S. Lincoln, The discipline and practice of qualitative research, In: N.K. Denzin and Y.S. Lincoln, (Eds.), Strategies of Qualitative Enquiry, 2008 , Sage; London, 1-44.

20

. M. Hammersley, What's Wrong with Ethnography?, 1992, Routledge; London.

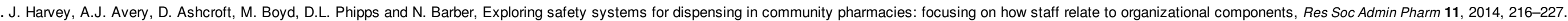

. S. Ziebland and A. McPherson, Making sense of qualitative data analysis: an introduction with illustrations from DIPEx (personal experiences of health and illness), Med Educ 40, 2006, 405-414.

23

. A. Blenkinsopp and C.M. Bond, The potential and pitfalls of medicine management: what have we learned so far?, Dis Manag Health Out 16, 2008, 79-86.

24

. H. Mcmullen, C. Griffiths, W. Leber and T. Greenhalgh, Explaining high and low performers in complex intervention trials: a new model based on diffusion of innovations theory, Trials 16, 2015, 242.

25

. T.R. Hopp, E.W. Sørensen, H. Herborg and A.S. Roberts, Implementation of cognitive pharmaceutical services (CPS) in professionally active pharmacies, Int J Pharm Pract 13, 2005, 21-31.

26

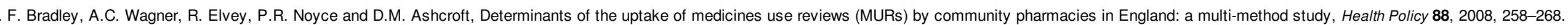

27

. A. Latif, H. Boardman and K. Pollock, A qualitative study exploring the impact and consequence of the medicines use review service on pharmacy support-staff, Pharm Pract 11, $2013,118-124$.

. M. Rosenthal, Z. Austin and R.T. Tsuyuki, Are pharmacists the ultimate barrier to pharmacy practice change?, Can Pharm J 143, $2010,37-42$.

29

. A. Latif, K. Pollock and H. Boardman, Understanding the patient perspective of the English community pharmacy Medicines Use Review (MUR), Res Social Adm Pharm 9, $2013,949-957$.

30

. A. Blenkinsopp, C. Bond, G. Celino, J. Inch and N. Gray, Medicines use review: adoption and spread of a service innovation, Int J Pharm Pract 16, 2008, 271-276.

31

. A. Latif, K. Pollock and H. Boardman, Medicines use reviews: a potential resource or lost opportunity for general practice?, BMC Fam Pract 14, $2013,57$.

32

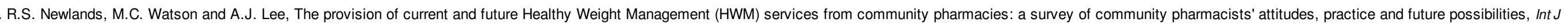
Pharm Pract 19, 2011, 106-114.

33

. A.S. Roberts, S.I. Benrimoj, T.F. Chen, K.A. Williams and P. Aslani, Practice change in community pharmacy: quantification of facilitators, Ann Pharmacother 42, $2008,861-868$.

34

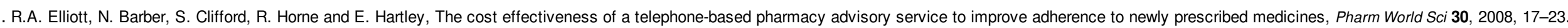




\section{elsevier_RSAP_690}

35

Centre for Postgraduate Pharmacy Education, Consultation Skills for Pharmacy Practice, 2014, University of Manchester; Manchester.

36

B. Lucas and A. Blenkinsopp, Community pharmacists' experience and perceptions of the New Medicines Service (NMS), Int J Pharm Pract 2015, http://dx.doi.org/10.1111/ijpp.12180.

37

. M.C. Stone and H.C. Williams, Clinical pharmacists in general practice: value for patients and the practice of a new role, Br J Gen Pract 65, 2015, 262-263.

\section{Supplementary data}

Multimedia Component 1

\section{Queries and Answers}

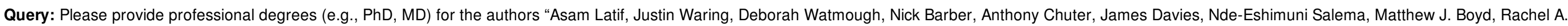
Elliott" in the author group, as it is mandatory as per journal style.

Answer: Done

Query: Please verify the article footnote 'Declaration of competing interests' and correct if necessary.

Answer: Yes this is correct

Query: Please provide the grant number for 'Department of Health Policy Research Programme' if any.

Answer: The award number has been provided

Query: Please check the layout of Table 2.

Answer: Please can you shorten the first column so that more space can be dedicated to the last column

Query: Please confirm that given names and surnames have been identified correctly.

Answer: Yes 